\title{
Solar Cooker
}

\author{
Ing.Phd Elhadji Amadou Hamissou ${ }^{1}$, Ing. Labo Sanoussi ${ }^{2}$; \\ Ing. Ousmane Inoussa ${ }^{2}$ \\ ${ }^{1}$ (Teacher and research at the University of Maradi, Republic of Niger) \\ 2 (workshop training school Dan-Kassawa Maradi-Republic of Niger)
}

\begin{abstract}
This article was the object of a practical work of physics applied with the first-year students in renewable energy, within the framework of the works a part is dedicated to the technique of weld, metallic construction and the other one to the education to the environment and sustainable development. It becomes integrated perfectly into the current program of this sector (thermal source, efficiency, been of characteristics, modeling). The objective is to model a solar cooker then to see how we can design it by means of accessible material. We compare the results obtained under miscellaneous slopes and period of the year.
\end{abstract}

Keywords: solar cooker, Niger cooker, renewable energy Niger, solar cooking, sabo murfu

\section{INTRODUCTION}

The solar cooker " SABO MURFU V1"* - is a simple device which transforms the solar radiations into heat for the preparation of the food without running Gas, oil or the electrical energy. The principle functioning of the solar cooker is based the principle of the parabola that is the solar orientation of shelves towards the center. On the parabola the concentrator focuses sunbeams, where a hole is realized and where we put the dish or the pot. The concentrator is asymmetric. So, he can get all the sunbeams. It also avoids that the pot and the cook made shade on the concentrator. The parabola is rotary on $360^{\circ}$

\section{HEADINGS}

We distinguish four types of sun rays: global, direct, diffuse and reflected. The global radiation corresponds to the energy illumination of a unit horizontal surface during a given period. The sun rays cross the atmosphere, which: absorb a part (29\%) and return towards the space a part (23\%). The diffuse and direct sun rays are called global incidental radiation arriving at the ground.[1], [2] ,[3] , [4]

\section{Model distribution of sunshine}

\section{INDENTATIONS AND EQUATIONS}

$$
I(d, t)=I_{\max }(d) \sin \left(\frac{\pi t}{D L(d)}\right)
$$

The time $t$ is the decimal hour ( $t=0$ in the sunrise), DL $(d)$ is the duration of day $d$ is $\operatorname{Imax}(d)$ is the value of $I$ $(d, t)$ in $t=D L(d) / 2$. Because the quantity of accumulated solar energy $G(d)$ is obtained by the integration I $(d, t)$ on the day of, $G(d)$ is expressed by:

$$
\begin{aligned}
& G(d)=\int_{0}^{D L(d)} I_{\max }(d) \sin \left(\frac{\pi t}{D L(d)}\right) d t \\
& \left.I_{\max }(d)=\frac{\pi G(d)}{2 D L(d)}\right)
\end{aligned}
$$

The duration of day $\mathrm{d}$ is given by the equation:

$$
D L(d)=G M T_{\text {sunset }}(d)-G M T_{\text {sunrise }}{ }^{(d)}
$$

With :

$$
G M T(d)=12-T_{e}(d)+\frac{L+\in \cos ^{-1}(\operatorname{tg}(\delta(d)) \operatorname{tg}(\phi))}{15}
$$




$$
T_{e}(d)=0.123 \cos (N(d)+87)-\frac{\sin (2(N(d)+10))}{6}
$$

$\delta(d)=23.45 \cos (N(d)+10)$

$$
N(d)=0.988[D(d)+30.3(m-1)]
$$

GMT ( $d$ ) represent the hours of rise and day sunset $d$; with $=1$ for the sunset and $=1$ for the rise. $L$ the longitude is, $\phi$ is the latitude, Te(d) is the equation of time (in the hour), $\delta(\mathrm{d})$ is the declension (in degree). D (d) represent the day number in the month, $\mathrm{m}$ the number of the month ( January $=1$ ), and $\mathrm{N}(\mathrm{d})$ the day number in the year. (Fig.1.0)

\section{Model distribution of temperature}

This model uses the minimal ambient temperature Tmin $(d)$ and maximal Tmax $(d)$ (measured or estimated) for one day $d$ to express the distribution, under sinusoidal shape, the ambient temperature $T(d, t)$ during all day $\mathrm{d}$ :

$$
T(d, t)=\frac{T_{\max }(d)+T_{\min }(d)}{2}+\frac{T_{\max }(d)-T_{\min }(d)}{2} \sin \left(\frac{\pi(t-1)}{12}\right)
$$

The time $t$ is counted since the sunrise for the day $d$.

All the sunbeams are focused in the center of the parabola.

$\mathrm{F}$ - The focal length between the origin $\mathrm{O}$ and thefoyer $\mathrm{F}$

The summit of the parabola is $\mathrm{O}$ (Pic.1.1)

Let $\mathrm{M}(\mathrm{Xo}, \mathrm{Yo})$ a point situated on the parabola the tangeante $\mathrm{M}$ has for equation $=1 / 2 \mathrm{XOX} / \mathrm{F}-\mathrm{Yo}$. The normal $M$ has for equation $Y=-2 x f / x o+2 f+y o$

$\mathrm{U}$ is in the middle of Oxo

$\mathrm{U}$ is in the middle of TM

$\mathrm{O}$ is in the middle of Tyo

The parabola is a curve the equation of which is $y=X^{2} / 4 f$ (Fig.1.2)

Equation of distribution of the heat in a homogeneous bar:

$\frac{\partial u}{\partial t}=\frac{k \partial^{2} u}{c \rho \partial x^{2}} \Leftrightarrow \frac{\partial u}{\partial t}=a^{2} \frac{\partial^{2} u}{\partial x^{2}}$

With

$$
a^{2}=\frac{k}{c \rho}
$$

(a is the coefficient of diffusivité thermal expressed in en $\mathrm{m}^{2} \cdot \mathrm{s}^{-1}$ ).

$\rho$ : factor of reflection

$\alpha$ : Factor of absorption or absorptivity

$\tau:$ Factor of transmission or transmissivité

we have naturally: $\rho+\alpha+\tau:=1$

Furthermore, any body which warms up emits in its environment a radiation of conversely proportional wavelength in its temperature. The law of Wien gives the wavelength of the maximum of emission, issue according to the body temperature

After all, a thermal solar cell has to accept the maximum of sun rays (high transmittance), absorb the major part (high absorbance ), emit it and let take out the least possible (transmittance reduced in the long waves). [5], [6]

\section{Heat balance of a sensor}

The useful power is the one who allows to warm the debit of coolant $\mathrm{m}$ of the temperature of entrance Tentry until the temperature of exit Texit:

$$
E u=m c p\left(T_{\text {exit }}-T_{\text {enttry }}\right)
$$

- E: the incidental solar power from the point of view of the sensor $\left(\mathrm{W} / \mathrm{m}^{2}\right)$ 
- Tm: the temperature averages of the sensor (approximation in the average between the temperatures of entrance and sensor's exit $\left({ }^{\circ} \mathrm{C}\right)$.

- Text: the outside temperature $\left({ }^{\circ} \mathrm{C}\right)$

and parameters defining the sensor:

$\beta$ : the optical factor of the sensor, which is the relationship enters the period of sunshine absorbed by the absorber and the incidental period of sunshine on the glazing. This optical factor is the product of the factor of transmission of the glazing $\tau$ by the coefficient of absorption of the absorber $\alpha$.

$\mathrm{K}$ : The coefficient of thermal decreases $\left(\mathrm{W} /{ }^{\circ} \mathrm{C}\right)$

The heat balance in still regime of the sensor expresses that the absorbed power $\tau \alpha \mathrm{E}$ divides up between the useful Had power Eu and the heat losses:

$$
\tau . \alpha . E=K(\text { Tm }- \text { Tout })+m c p(\text { Texit }- \text { Tentry })
$$

$\mathrm{Eu} \mathrm{Had}$ is thus equal to the part of the incidental power crossing the glazing and absorbed by the absorber, decreased in the thermal decreases (proportional away from temperature between the sensor and the atmosphere):

$$
E u=\beta . E . K(T m-T o u t) \quad[7],[8]
$$

IV.

FIGURES

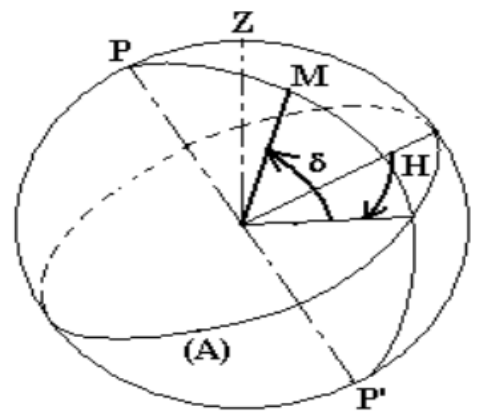

Fig.1.0 the declension $\delta$ of sun (in degree).

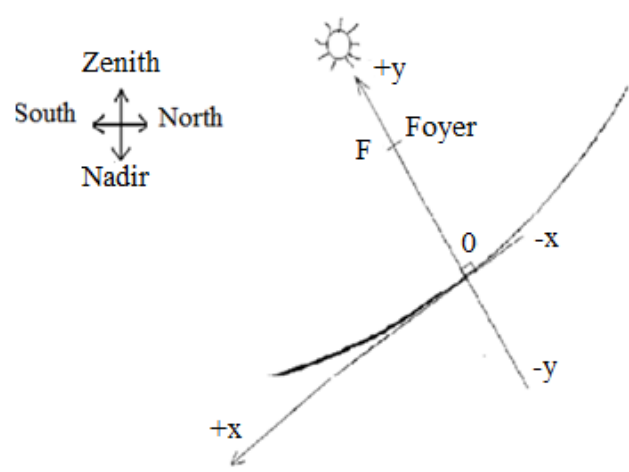

Fig.1.1 Construction of the parabola.

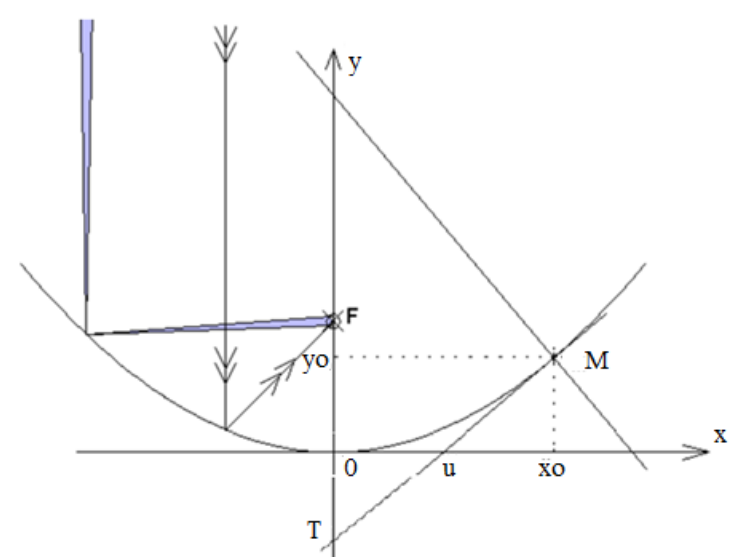

Fig.1.2 Determination of the center of the parabola. 
Fig.1.3 Solar radiation in different corner in Republic of Niger
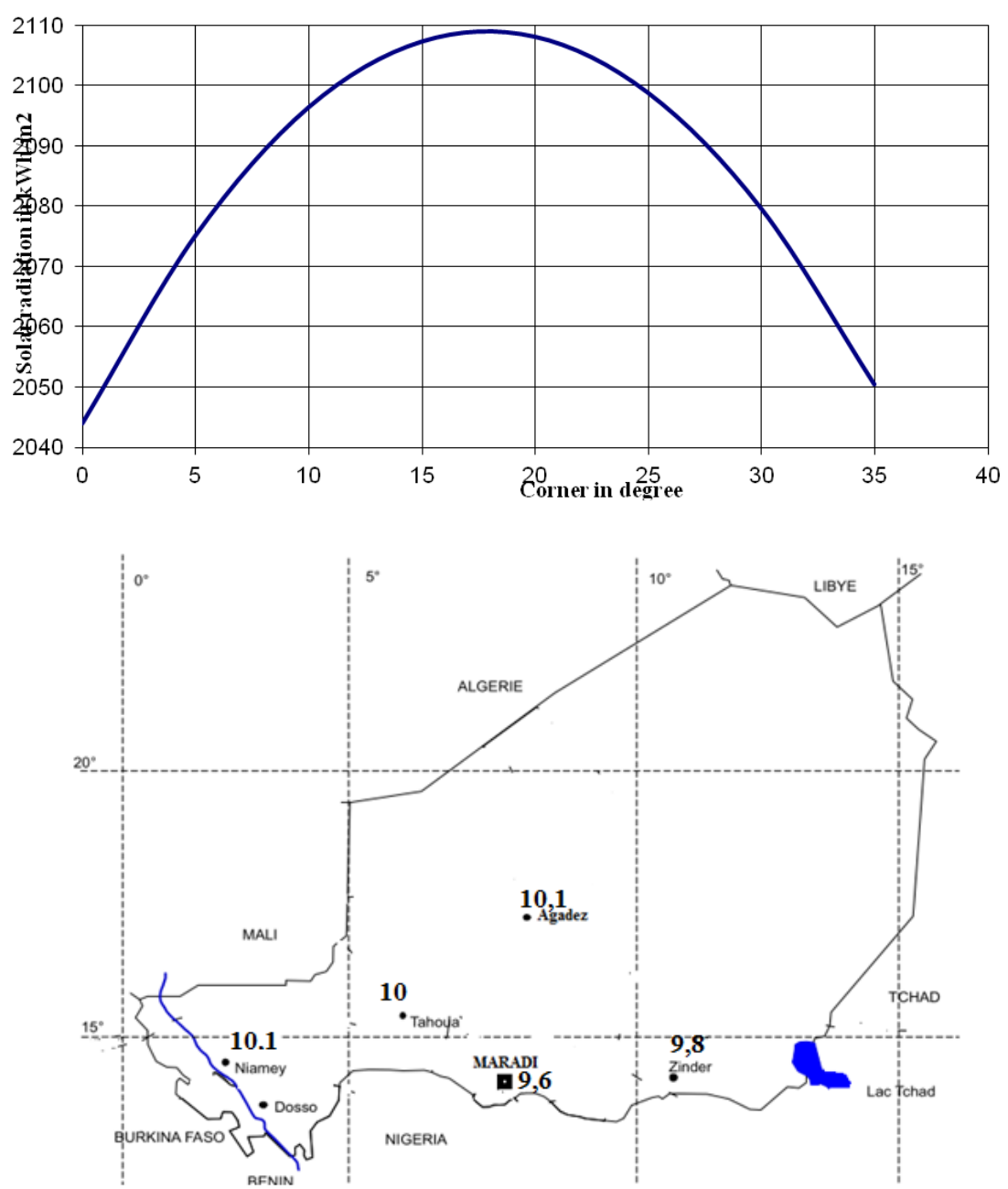

Fig.:1.4 Insolation(sunstroke) in Republic of Niger (december)

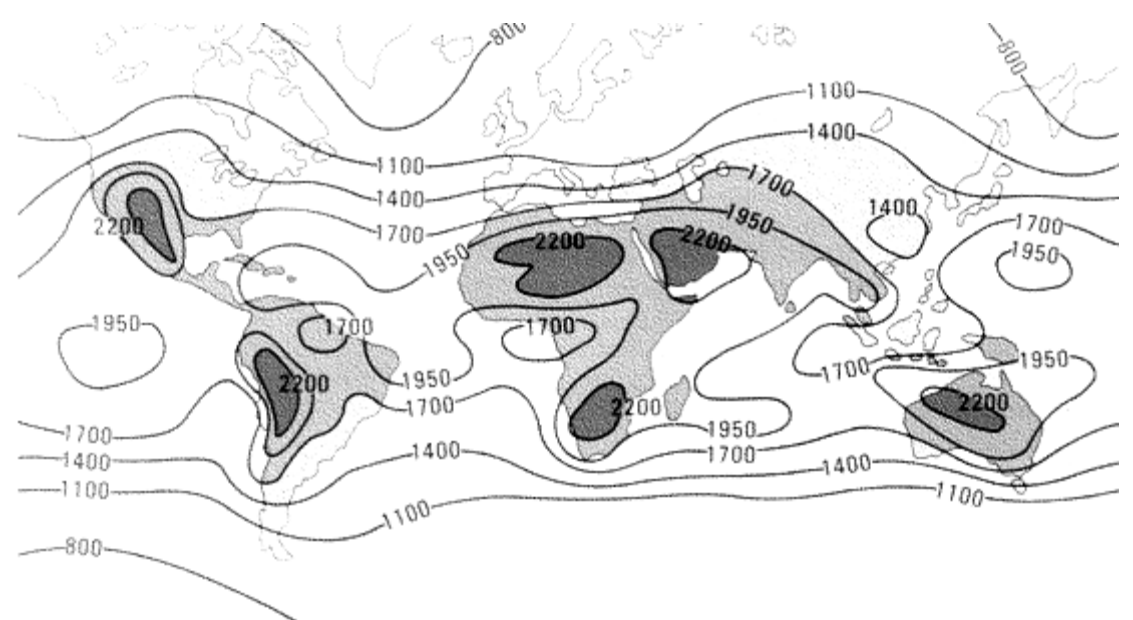

Fig.: 1.5 World Map for solar radiation 

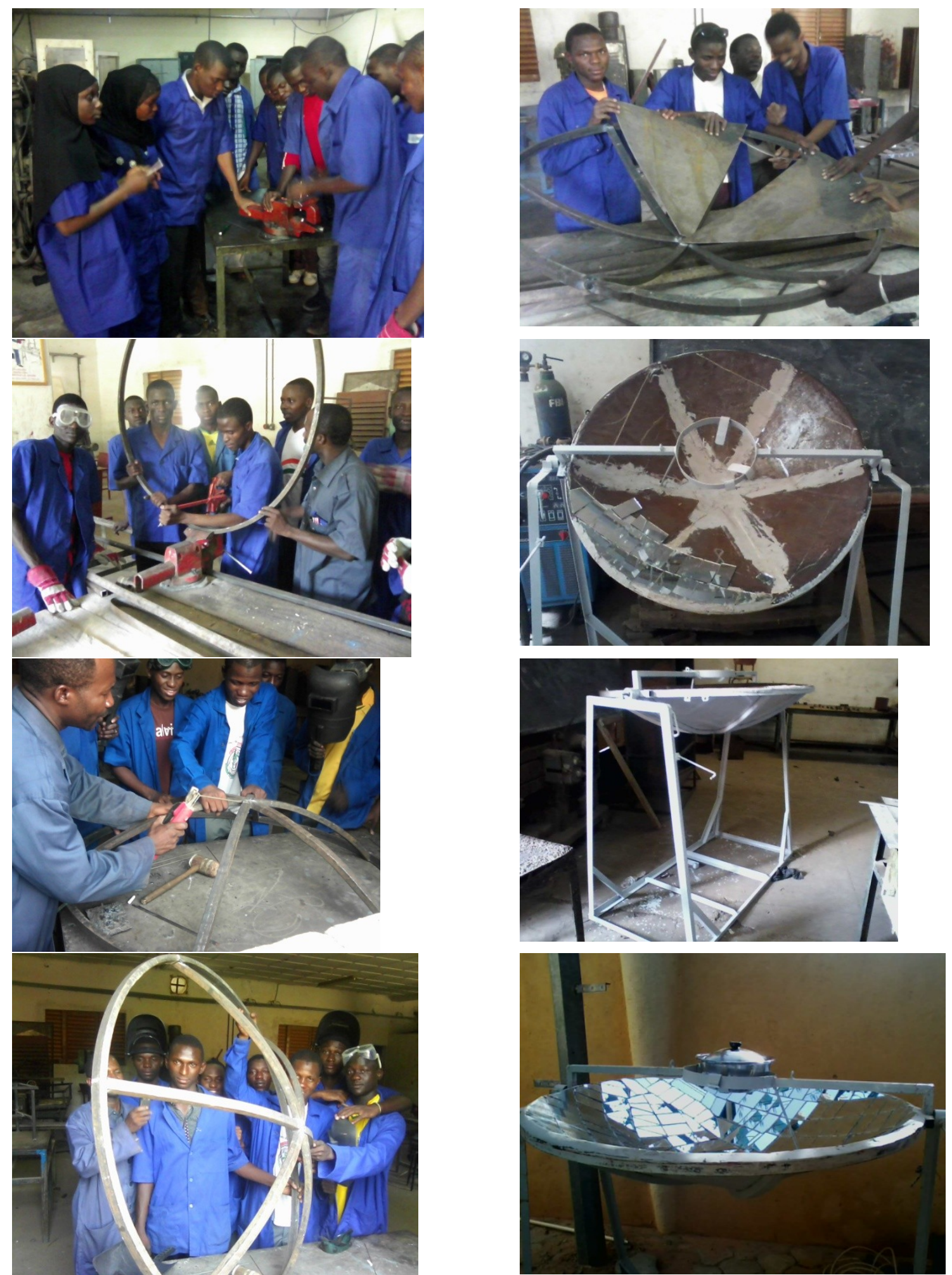

Fig. 1.6 Students in pratical metallic construction (Solar cooker)

\section{CONCLUSION}

This study allowed us to see in the context of the republic of Niger the efficiency of a solar cooker. The study showed us that the proper functioning of solar cooker near that 10 months in the year.

The solar cooker participates in the local economy, struggle against poverty and protects the environment. 


\section{Acknowledgements}

All my thanks to the foremen of the Technical Secondary school DAN-KASSAWA of Maradi and don't forget the serious of the students Renewable Energy University of Maradi Republic of Niger.

\section{REFERENCES}

\section{Books:}

[1] Methods of calculation of the renewable energies; VISSARIONOV Vladimir Ivanovitch and Deriojina J. V., H.K. Malinin, Burmisov A.A ., Kusnesov V.A.

[2] Duffie, Has. And John Beckman, William A. 2006: engineering of solar thermal processes, Wiley.

[3] Henning, HM on 2003: assisted solar air conditioning of buildings - A manual worker for the planners.

[4] Peuser, Has. Felix, Remmers, Karl-Heinz and Schnauss, Martin, on 2002: thermal solar systems, a good planning and of construction,

[5] THERMAL SOLAR ENGINEERING OF PROCESSED: Jon Duffie, WilliamA Beckman; John Wiley and Sounds: New-York

[6] FUNDAMENTAL OF HEAT TRANSFER: Frank Incropera, David p. Dewitt; John Wiley and Sounds, New- York

[7] Electric Conversion of the renewable energies ( CEER); MAHER Chaabene, Lecturer in the ISEC of SFAX

\section{Journal Papers:}

[8] International Organization for Standardization, on 1994: test methods of solar cells, HAVE it, Geneva * SABO MURFU VI : New Cooker version 1, In Hausa the principal language of Republic of Niger 